\title{
METROPOLIZAÇÃO DO ESPAÇO E IN-SEGURANÇA: REDES DE VIGILÂNCIA E MONITORAMENTO NA CONSTITUIÇÃO DE UMA “MEGARREGIÃO DE CONTROLE"
}

\author{
Metropolization of space and in-securuty: monitoring and surveillance networks in the \\ "Mega-Region of control" constitution
}

Felipe Rangel Tavares*

*Professor da Universidade Veiga de Almeida - tavares.geo@gmail.com.

\begin{abstract}
Resumo:
A metropolização do espaço é um processo político e, portanto, constituído de relações de poder. Tais relações, no âmbito da metropolização, podem ser analisadas a partir da tríade homogeneizaçãofragmentação-hierarquização, destacando-se esta última para focalizar os dispositivos, técnicas e estratégias de segurança que tem papel fundamental na formação das megarregiões e na sustentação de seus centros de poder - indispensáveis à governança metropolitana. Neste sentido, se Rio de Janeiro e São Paulo constituem uma megarregião e, se as funções de direção e comando dos centros de poder distinguem-se pelo grau de hierarquia, cabe-nos questionar como essas "megarregiões de controle" se constituem e se impõem sobre outras frações do espaço.
\end{abstract}

Palavras-chave: Metropolização; in-segurança; megarregião, redes.

\begin{abstract}
:
The metropolization of space is a political process and, therefore, constituted of relations of power. These relationships, within the scope of metropolization, can be analyzed from the homogenization-fragmentationhierarchy triad, highlighting the latter to focus on the safety devices, techniques and strategies that play a fundamental role in the formation of mega-regions and the support of their centers of power - indispensable to metropolitan governance. In this sense, if Rio de Janeiro and São Paulo constitute a megarregion, and if the functions of direction and command of power centers are distinguished by the degree of hierarchy, it is up to us to question how these "mega-regions of control" constitute and impose themselves over other fractions of space.
\end{abstract}

Key-words: metropolization; in-security; mega-region; networks.

\section{Introdução}

Observamos que, a partir da emergência das tecnologias de informação e comunicação, a hierarquização do espaço vem se desempenhando, predominantemente, não mais na modalidade piramidal, mas, de maneira reticular, isto é, a partir das redes que estruturam o território e garantem sua coesão. Portanto, as redes constituem não somente uma condição, mas, sobretudo, um meio pelo qual as técnicas e tecnologias voltadas ao controle e segurança da população se exercem no curso do processo de metropolização do espaço. 0 processo de hierarquização do espaço estrutura e ordena as formas-conteúdo de acordo com as suas funções. Dentre tais funções, estão aquelas ligadas ao controle e à segurança, correspondendo aos "centros de poder" dos quais partem as normas, direções e decisões. Na esfera de uma "sociedade do controle" ou de "segurança", tais centros atuam na programação, monitoramento e vigilância da vida cotidiana na metrópole. São exemplos de tais 
centros, os "megadispositivos urbanos" (HAESBAERT, 2015) que compõem o Centro de Operações Rio (COR) e os Centros Integrados de Comando e Controle (CICC). De acordo com Haesbaert (2015):

\begin{abstract}
No bojo das transformações urbanas e como um requisito internacional para a recepção da Copa do Mundo de 2014 e das Olimpíadas de 2016, o Rio de Janeiro passou a sediar, a partir de 2011, um dos mais sofisticados centros de televigilância do mundo, o Centro de Operações Rio e, a partir de 2013, um centro mais específico de segurança, em seu sentido militar, o CICC. Essa proliferação de núcleos de monitoramento, que se deu em várias cidades brasileiras a partir da realização da Copa do Mundo de 2014, representa a instituição de um novo megadispositivo urbano que, a partir de agora, tende a ser um componente indispensável no ordenamento dos espaços decisórios, centrais das grandes metrópoles - dentro da lógica (...) das sociedades denominadas por alguns de "controle" ou "de segurança". (HAESBAERT, 2015, p.229).
\end{abstract}

Ao nos debruçarmos sobre um processo que estrutura e integra (coesão) o espaço da metrópole, dando ênfase à hierarquização para focalizar essa dinâmica, não podemos olvidar que tal processo compõe uma tríade, a saber, homogeneização-fragmentação-hierarquização. Deste modo, faz sentido pensar que o processo de hierarquização ordena os fragmentos de um espaço que, embora esteja submetido a uma tendência homogeneizadora, é continuamente diferenciado segundo as dinâmicas de des-valorização do solo urbano, concebido como uma mercadoria. Esse espaço corresponde ao espaço da sociedade capitalista, homogêneo, fragmentado e hierarquizado. A fim de evidenciar as determinações e condições espaciais no âmbito do processo de metropolização, quando enunciamos "megarregiões de controle", propomos uma análise do fenômeno da vigilância e monitoramento em escala regional, ressaltando as relações de dominação e controle do espaço, ou seja, (espacializ)ações (e condições) de comando.

A dimensão da hierarquização evidencia a relação entre metropolização, in-segurança e biopoder, fundamentais na configuração de "espaços de comando". Denominaremos como "espaços de comando" aqueles que, no processo de hierarquização, constituem o domínio do poder e do comando, "que são instrumentais para garantir a totalidade do conjunto" (LENCIONI, 2010). São os espaços que exprimem o cotidiano programado e instauram o controle das práticas, a disciplina, a vigilância e o monitoramento. Espaços que, nas palavras de Milton Santos (2006), são uma estrutura de controle e limite às ações. A partir da noção de "Meio" (FOUCAULT, 2008) podemos tratar simultaneamente da problemática do (bio)poder (in-segurança, controle e comando) e da circulação (de bens, e principalmente, da população), questão crucial à compreensão da dinâmica das aglomerações difusas polinucleadas.

\title{
2. Metropolização e in-segurança
}

É preciso reconhecer que a história urbana dos dias atuais é determinada pelo processo de metropolização do espaço, uma nova fase de desenvolvimento do processo de urbanização, contudo, de natureza distinta, como afirma Lencioni (2006). O processo de metropolização condiciona $e$ produz a experiência do espaço-tempo contemporâneo, para corresponder às necessidades impostas pelo capital. 0 processo de metropolização do espaço pode ser caracterizado pelo desenvolvimento de aspectos que "impregnam o espaço de características metropolitanas" (LENCIONI, 2006). Que características são essas? Àquelas relacionadas à administração e gestão do capital, como também, relativos à esfera pública, sendo a concentração de tais serviços uma necessidade e condição à reprodução capitalista e sua viabilização política - ou seja - funções de serviços avançados e fomento de redes e infraestruturas que garantam a circulação e os fluxos (materiais e imateriais), de mercadorias, informações e pessoas.

Todavia, não se deve confundir o processo de metropolização com a institucionalização das regiões metropolitanas. E, por outro lado, não se deve negligenciar a dimensão política de tais processos, neste caso, a vontade política que caracteriza a institucionalização das regiões metropolitanas a partir da década de 1970, como também a metropolização como processo político

ParaOnde!?, Porto Alegre, v.11, n.1, p.105-113, 2019. http://seer.ufrgs.br/paraonde

Edição Especial: “Geografia e transformações socioespaciais: dinâmicas agrárias e políticas do desenvolvimento regional” 
para além do poder institucional do Estado como forma de organização político-territorial. De acordo com Souza (2006, p.34), por meio das políticas, as regiões metropolitanas contribuíram para o elo da lógica capitalista: as prioridades governamentais se alinham conforme os interesses dos grandes agentes econômicos. A metropolização é um processo político.

Concordamos com Lefebvre (2008) em suas reflexões acerca da política e do espaço e, a partir de sua teoria do espaço social como produto social, podemos focalizar a dimensão política, inerente ao processo de metropolização. Para Lefebvre, o espaço sempre foi político, ideológico e estratégico: “o espaço é politizado porque está inserido em estratégias conscientes ou inconscientes" (idem, p.67). No âmbito da metropolização do espaço, que estratégias são essas que determinam o caráter político do processo? A resposta reside no desenvolvimento de condições metropolitanas imprescindíveis para a reprodução do capital, uma determinação do momento histórico contemporâneo (LENCIONI, 2006, p.48-49).

Ao apresentar alguns pontos comuns característicos de uma metrópole, Lencioni (2006, p.45) destaca: a concentração de serviços privados e públicos; a metrópole enquanto um ponto de grande densidade de emissão e recepção dos fluxos de bens, serviços, pessoas, informação e comunicação; a metrópole enquanto um nó significativo de redes (transporte, informação, comunicação, cultura, inovação, consumo, poder e cidades). A concentração de serviços, os fluxos permanentes e as redes aparecem como elementos determinantes do processo de metropolização. A concentração de serviços de ordem superior expressa a função de direção e comando dos centros: são aqueles voltados para administração e gestão do capital das grandes empresas, também relativos ao setor financeiro e aqueles relativos à esfera pública - como os da administração pública e os relacionados ao controle político; uma necessidade e condição para garantir a gestão da reprodução do capital (idem, p.46). As redes e os fluxos se referem aos novos arranjos e dinâmicas territoriais que emergem das novas formas de organização da produção e da circulação (Lencioni, 2006b, p.69), expressando estratégias que buscam satisfazer a necessidade que o capital tem de abreviar o tempo total de rotação do capital (LENCIONI, 2010).

Neste sentido, como demonstra Lencioni (2006), enquanto a ideia de metrópole diz respeito às cidades, a noção de metropolização relaciona-se com o espaço e à produção do espaço; na perspectiva de Carlos (2015), "a metrópole é condição geral da produção, o que impõe uma determinada configuração espacial", ou seja, embora relacionado à cidade e ao urbano, mas para além deles, o "espaço da metropolização" emerge como "o novo centro da acumulação e da produção das condições urbanas" (LENCIONI, 2010). Como núcleo metropolitano, em termos de relações de poder, a cidade do Rio de Janeiro se constitui como centro de comando, controle e decisões estratégicas (na acepção estrita, isto é, militar, e em sentido amplo).

Quando abordamos a questão da organização e controle do território, a partir da emergência de centros de poder, direção e comando, caminhamos no sentido de evidenciar a dimensão política do processo de metropolização, presente nas estratégias que determinam o momento histórico contemporâneo. Tratando-se do momento atual, emerge uma problemática fundamental para o entendimento da sociedade, relacionado ao risco, ao medo e a in-segurança (BECK, 2011; BAUMAN, 2008, 2009; FOUCAULT, 2008; HAESBAERT, 2014-2015, SOUZA, 2008). É nesta perspectiva que, ao escrever "política", inserimos o prefixo "bio" entre parênteses, para focalizar os dispositivos, técnicas e estratégias de segurança que tem papel fundamental na formação das megarregiões e na sustentação de seus centros de poder - indispensáveis à governança metropolitana. De acordo com Haesbaert (2014, p.157) a insegurança passa a ser tomada como "um modo de gestão da vida coletiva", acionando o Estado e as classes hegemônicas pela via da gestão dos riscos e das ameaças; deste modo, as técnicas de segurança "têm na modificação do espaço e do território um de seus elementos constituintes fundamentais" (idem, p.163). Segundo Foucault (2008, p.28), os dispositivos de segurança "trabalham, criam, organizam, planejam um meio antes mesmo da noção ter sido formada e isolada". Esta noção de "meio", proposta pelo autor, constitui um campo de intervenção que "procura atingir a população", considerada como uma multiplicidade de indivíduos que são e que

Para0nde!?, Porto Alegre, v.11, n.1, p.105-113, 2019. http://seer.ufrgs.br/paraonde

Edição Especial: “Geografia e transformações socioespaciais: dinâmicas agrárias e políticas do desenvolvimento regional” 
só existem profunda, essencial e biologicamente ligados à materialidade dentro da qual existem (idem).

0 meio vai ser, portanto, aquilo em que se faz a circulação. 0 meio é um conjunto de dados naturais, rios, pântanos, morros, é um conjunto de dados artificiais, aglomeração de indivíduos, aglomeração de casas, etc. (...) Portanto, é esse fenômeno de circulação das causas e dos efeitos que é visado através do meio. (FOUCAULT, 2008, p.28).

A análise de Michel Foucault (2008) acerca dos mecanismos de segurança e sua noção de "meio" são fundamentais para compreendemos os processos em curso, que, diferente dos mecanismos da lei e da disciplina,

(...) vai procurar criar um ambiente em função de acontecimentos ou de séries de acontecimentos ou de elementos possíveis, séries que vai ser preciso regularizar num contexto multivalente e transformável. (...) 0 espaço em que se desenrolam as séries de elementos aleatórios é, creio, mais ou menos o que chamamos de meio. (...) É, portanto, o suporte e o elemento de circulação de uma ação. (FOUCAULT, 2008, p.27). [grifo nosso].

Sendo assim, de acordo com Foucault, o que está em questão na noção de meio é a circulação, a fluidez. 0 que está em questão é a produção e organização do espaço que, a partir do processo de metropolização, "implica (...) um território no qual os fluxos de pessoas, de mercadorias ou de informações são múltiplos, intensos e permanentes" (LENCIONI, 2006, p.48). Podemos enxergar aqui um nexo entre circulação, fluxos e controle do/no território. Contudo, enquanto há uma ênfase no investimento e desenvolvimento de mecanismos de controle e gestão das atividades econômicas imprescindíveis para acumulação do capital, localizadas, como diria o professor Milton Santos, nos espaços luminosos, as zonas opacas ficam abandonadas... ou, melhor, são alvo de outros tipos de investimentos e mecanismos de controle, àqueles ligados ao "meio": programação, monitoramento, vigilância e reclusão. É possível perceber uma multiplicidade de inter-relações, que são relações de poder, criando condições para a circulação e sendo condicionadas pelos fluxos.

A noção de "meio" nos auxilia a tratar a problemática biopolítica (controle, segurança) da circulação (bens, pessoas, informação), questão crucial à compreensão da dinâmica das aglomerações difusas polinucleadas. A partir de tal definição biopolítica proposta por Foucault, o que deseja-se apreender com a noção de meio são os fluxos, ou melhor, "o aumento - e, correlativamente, o controle - da circulação, da fluidez no/do espaço" (HAESBAERT, 2014, p.174). É a partir dessa noção que capturamos uma relação entre segurança e metropolização, enfatizando sua dimensão (bio)política, uma vez que os serviços de ordem superior da esfera pública e privada se debruçam, cada vez mais, sobre questões relacionadas à vigilância, monitoramento e controle da circulação e dos fluxos no espaço da urbanização dispersa.

No próximo item discutiremos a constituição de "megarregiões de controle" a partir da tríade homogeneização-fragmentação-hierarquização, enfatizando a dimensão da hierarquização, expressão da espacialidade do poder, da economia e da política (LENCIONI, 2015, p.41). Exemplificamos essa relação a partir dos Centros Integrados de Comando e Controle (CICC; figura 1), que compõem redes de vigilância e monitoramento, criadoras de uma coesão no âmbito da segurança, e são responsáveis pela generalização do controle em escala regional.

\section{Redes, coesão e coerção: a constituição de "megarregiões de controle".}

Como dito anteriormente, a enorme densidade de fluxos e as redes materiais e imateriais são componentes essenciais na dinâmica da metropolização e da formação de megarregiões. 0 território que se implica pelo processo de metropolização caracteriza-se pelos múltiplos, intensos e permanentes fluxos de pessoas, mercadorias e informações (LENCIONI, 2006, p.48). Os fluxos evidenciam as transformações que marcam a história urbana atual, onde os fenômenos de dilatação e a dispersão predominam sobre as demais formas do urbano (LENCIONI, 2015b, p.7). De acordo com a autora, é indispensável haver uma unidade interna, uma coesão, a constituição de uma totalidade 
para que a região se constitua enquanto tal. Neste sentido, os fluxos são elementos constitutivos da integração. Ao tratar sobre a abordagem de megalópoles por Gottmann, Lencioni afirma que:

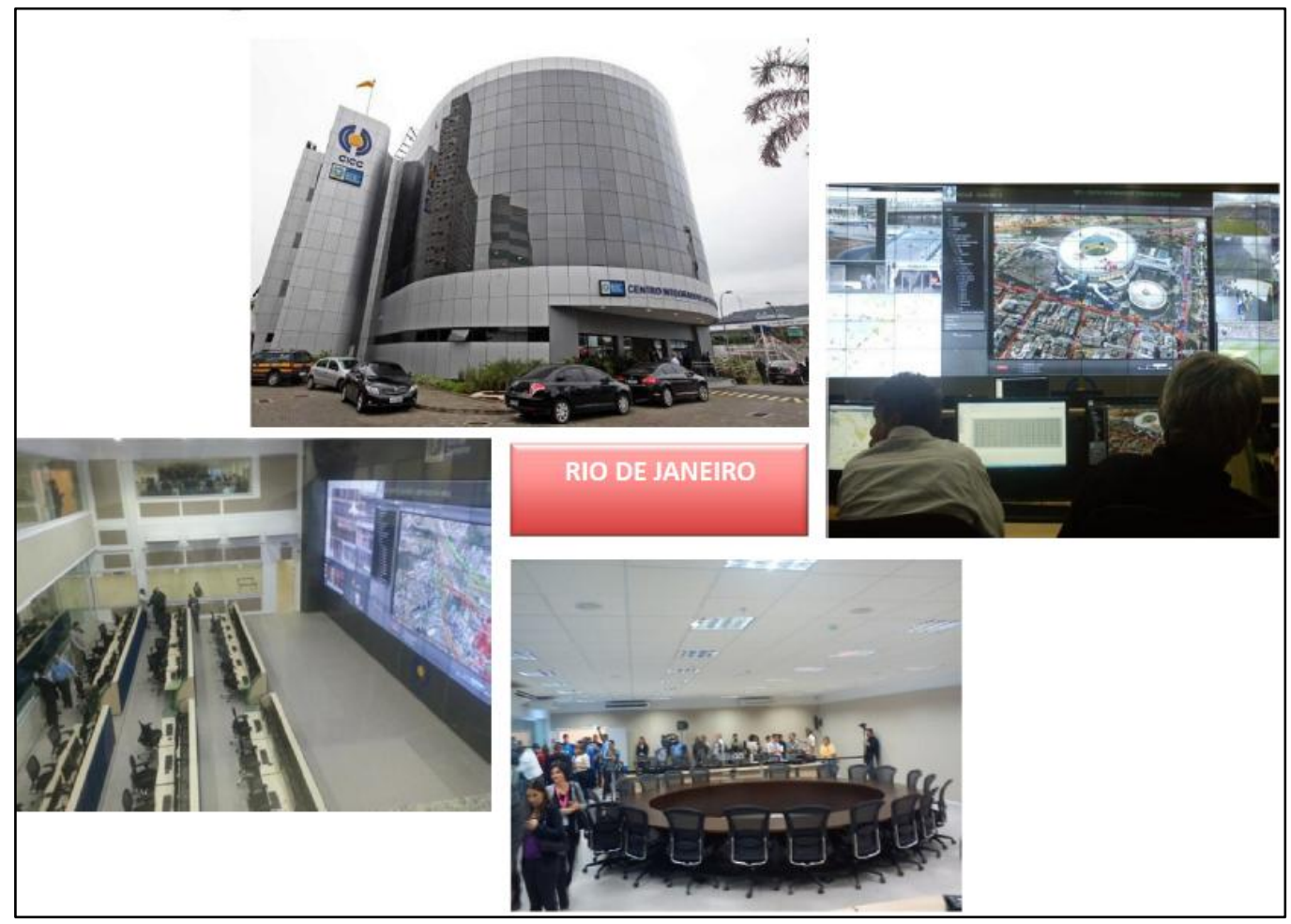

Figura 1. Centro Integrado de Comando e Controle, Rio de Janeiro. Fonte: Secretaria Executiva de Segurança para Grandes Eventos (SESGE).

Os fluxos, os movimentos, as ligações (linkages) entre as partes, bem como as complementaridades entre partes e funções, que se dão pela mediação de diversas dinâmicas e processos e que se desenvolvem no interior da região, são constitutivos da integração. Por isso, a megalópole como região, como região urbana e não como área urbana deve apresentar coesão interna, deve apresentar integração socioespacial. Isso significa dizer que não é qualquer área urbana onde predomina a dispersão que se constitui numa metrópole. (LENCIONI, 2015, p.49).

Apresentando uma discussão acerca de totalidade e fragmentação, a autora demonstra que a integração é o elemento-chave que assegura a coesão na dispersão, isto é, que garante o conjunto. Para Lencioni (2015b) é o exame da integração na dispersão que permite compreender os limites da urbanização dispersa, pois é a integração que permite entender a tensão que existe entre fragmentação e totalidade. Portanto, ao utilizar a palavra região, a autora pretende expressar o sentido de integração,

indispensável para se compreender uma urbanização difusa e o desenvolvimento de regiões urbanas extensas territorialmente e em coalescência, a expressar unidade na fragmentação. (LENCIONI, 2015b, p.10).

A integração/coesão é discutida por Lencioni $(2006 \mathrm{~b}, 2010)$ a partir do conceito das redes, que se constituem como forças produtivas fundamentais de uma economia globalizada e evidenciam a dimensão do espaço enquanto meio, isto é, como mediação necessária à reprodução do capital em escala globalizada. Além disso, ao classifica-las em dois tipos - redes de proximidade absoluta e rede de proximidade relativa - afirma seu papel enquanto um dos elementos estruturadores de novos

ParaOnde!?, Porto Alegre, v.11, n.1, p.105-113, 2019. http://seer.ufrgs.br/paraonde Edição Especial: “Geografia e transformações socioespaciais: dinâmicas agrárias e políticas do desenvolvimento regional” 
arranjos territoriais, como o da cidade-região (LENCIONI, 2006b, p.71); por meio delas se garante a continuidade na descontinuidade, a unidade na fragmentação, como também, a distinção e separação do que tem capacidade de se conectar daquele que não o tem (LENCIONI, 2010). Podemos observar a evidência dessas redes na figura 2 :

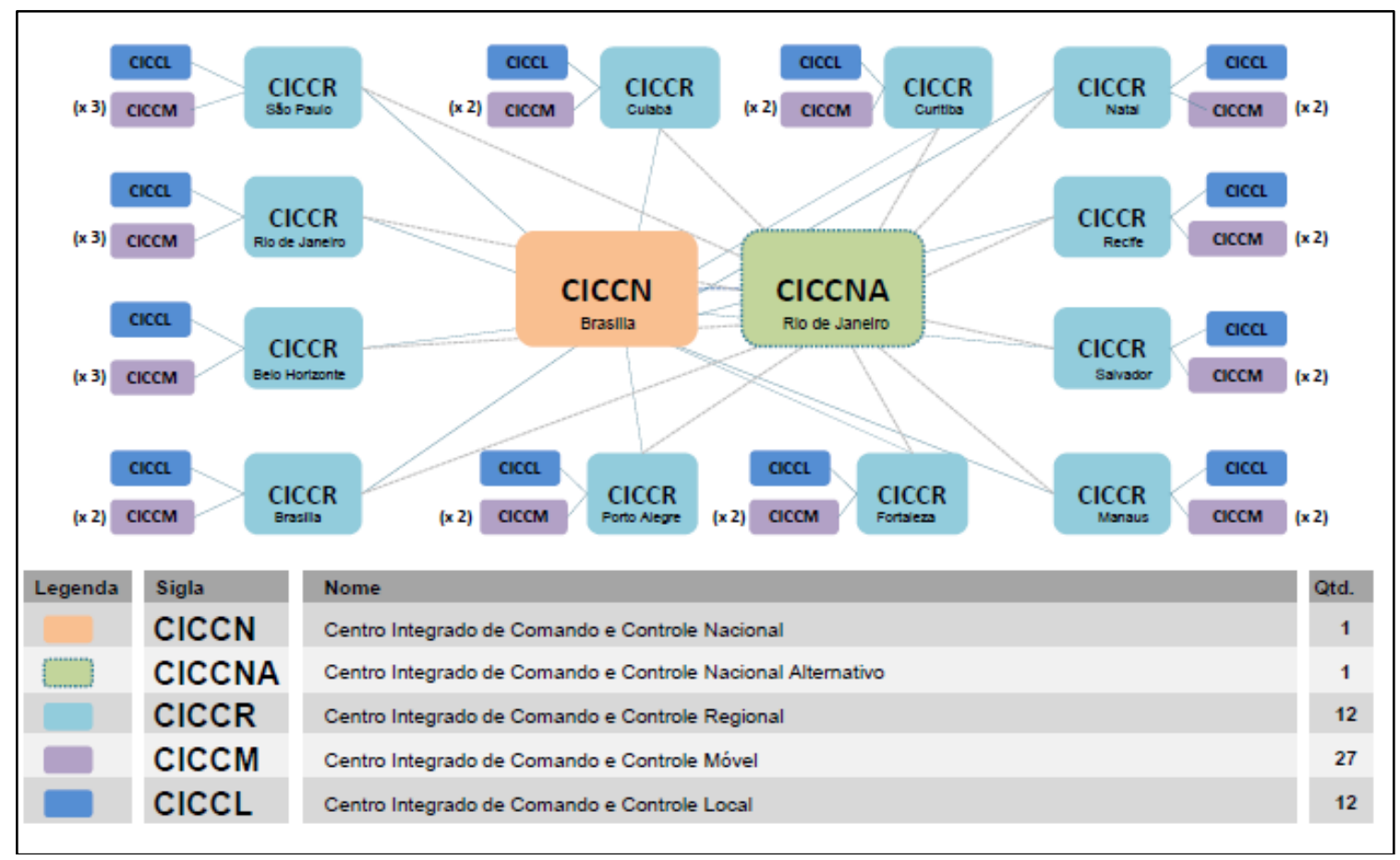

Figura 2. 0 Esquema apresenta a integração reticular dos Centros Integrados de Comando e Controle no Brasil. Cada retângulo representa uma capital, que se conecta aos centros principais, no centro da figura.

Como expusemos anteriormente, a metropolização do espaço - enquanto processo biopolítico em sua relação com a dimensão da in-segurança - estrutura e ordena territórios a partir de tecnologias e dispositivos de vigilância e monitoramento cujo objetivo é a gestão da vida coletiva da população. Tais componentes devem ser vistos como característicos da nova fase da história urbana, uma urbanização dispersa ou planetária numa "sociedade biopolítica de in-segurança" (HAESBAERT, 2014). A explosão desse processo e seus limites são apreendidos na análise dos elementos que promovem a integração - os fluxos e as redes - o que, portanto, coloca-nos diante da região como categoria capaz de focalizar, no âmbito da segurança, a constituição de uma "megarregião de controle", uma vez que a natureza da coesão constituidora da regionalização é o controle da população.

De acordo com Lencioni (2015), uma megarregião não é apenas estruturada pelas vias de circulação. Embora a vasta dimensão territorial seja uma importante componente da megarregião, os fluxos imateriais (que fluem por uma densa rede de fibra ótica que compõem redes de informação e comunicação) são indispensáveis para pensar a descontinuidade que constitui a megarregião, principalmente por apresentar "fortes vínculos com a dinâmica global", ou, "uma escala global de relações" (LENCIONI, 2015, p.61).

Um outro aspecto já mencionado, é o de que embora os eixos de circulação viárias sejam estruturados do território, há que se levar em conta a rede de circulação imaterial que amalgama essa estrutura e aproxima e integra essa m egarregião aos fluxos e processos de diversas ordens e escalas (LENCIONI, 2015, p.62).

Nessa mesma direção, Lencioni (2017) aborda um processo de "metropolização regional policêntrica" cujo paradigma é a metropolização do espaço e a perspectiva é a da região. Podemos apreender o fenômeno de generalização de megadispositivos de vigilância e monitoriamento no interior de um processo de "metropolização regional" observando que o processo de metropolização 
desenvolve regiões policêntricas, isto é,

[um] processo de metropolização regional [que] produz uma região dispersa polinucleada, em que esses núcleos podem ser de igual ou de diferentes envergaduras. (...) A metropolização regional de agora é policêntrica, podendo até conter várias metrópoles. (LENCIONI, p2017, p.152). (Grifo do autor).

Mais uma vez, a autora afirma que o limite regional não é dado pelo recorte territorial, porém, pela integração interna desse conjunto que constitui uma totalidade, podendo haver descontinuidade, uma vez que, o que confere unidade à região é a coesão, como já discutido. Abordando a questão das escalas, Lencioni (2017, p.155) observa que "a região pós-metropolitana contém muitas escalas que se entrelaçam e se superpõem: a escala local, a regional, a nacional e a global". Neste sentido, diante da considerável densidade técnica dispersa (fibra ótica e fluxos de comunicação e informações) e da coesão no âmbito de uma biopolítica de segurança, podemos utilizar o arcabouço teórico-conceitual "metropolização-espaço-região" para discutir a constituição de uma "megarregião de controle" que integra diversas escalas em busca da vigilância e do monitoramento da população. Tais dinâmicas acentuam o caráter homogêno, fragmentado e hirarquizado do espaço moderno e afirmam a relevância da tríade homogeneização-fragmentaçãohierarquização para análise do processo de metropolização regional.

\section{Considerações finais}

Observa-se que ao abordar a integração como elemento que assegura a coesão na dispersão tratase de um espaço de natureza fragmentada, uma vez que se pretende garantir a unidade das partes de uma totalidade. É neste sentido que a autora oferece um recurso-chave à análise do espaço ao resgatar a tríade que considera o espaço da sociedade capitalista como homogêneo, fragmentado e hierarquizado (LENCIONI, 2010; 2015). A homogeneidade do espaço corresponde às semelhanças paisagísticas e similaridades (LENCIONI, 2015). Adere-se aos modelos de sucesso internacional que tornam as cidades meras-cópias de edifícios e arquitetura; a homogeneização se revela como tendência. Contudo, tal homogeneidade se fragmenta, mesmo que somente na aparência; Tanto nas formas quanto nas funções, é possível perceber o processo de fragmentação, assentada numa concepção de espaço e cidade como mercadorias para atender o mercado imobiliário.

Podemos perceber uma relação entre a tríade homogêneo-fragmentado-hierarquizado e outra tríade analítica, a saber, forma-função-estrutura. Em Lencioni (2010), observamos uma relação entre homogeneidade e as formas do espaço: as cidades, edifícios, centros comerciais, avenidas, segundo a autora, "atestam as equivalências, o mesmo". Em trabalho mais recente, Lencioni (2015) aponta também para as similaridades relativas ao processo de produção, isto é, na padronização dos procedimentos de produção do espaço construído, o que nos lembra do debate de Milton Santos (2006) acerca da unicidade da técnica. Fazendo referências às mesmas obras mencionadas, percebemos uma relação entre a fragmentação e as funções do espaço, uma vez que as formas desempenham funções que lhes são designadas - como moradia, lazer, negócios, controle: a fragmentação do espaço remete à divisão das formas-conteúdo segundo as diversas funções e usos que ele abriga. Por último, é possível perceber uma relação entre hierarquia e estrutura. De acordo com Lencioni (2010), "a hierarquização permite o domínio do poder e do comando, que são instrumentais para garantir a totalidade do conjunto". Para Milton Santos (2008), "estrutura implica a inter-relação de todas as partes de um todo; o modo de organização ou construção". Nesta perspectiva, há uma nítida referência à totalidade e organização - o modo de estruturação - dessa totalidade. Assim, a hierarquização, ao manifestar a dominação que assegura a unidade do conjunto, é um processo de ordenamento das partes cujas funções foram segmentadas no curso dos processos de homogeneização e fragmentação. Conforme Lencioni (2015), embora seja recorrente o uso da tríade analítica, muitas vezes ela termina por ser reduzida aos termos homogeneização- 
fragmentação, olvidando o termo hierarquização.

Cientes de que a problemática não se esgota nessas linhas e que o presente artigo pretende apresentar alguns desdobramentos de uma pesquisa ainda em andamento, desejamos colocar algumas considerações que julgamos relevantes quando abordamos o termo hierarquização. Neste caso, é válido repetir: a hierarquização é um processo de ordenamento das partes cujas funções foram segmentadas no curso dos processos de homogeneização e fragmentação. A hierarquização é um processo indispensável à fragmentação, uma vez que, enquanto ordena, ratifica funcionalidades, pré-estabelecendo ou prescrevendo usos sociais do/no espaço tempo. Da mesma maneira, é fundamental no âmbito da homogeneização, uma vez que opera por meio de um padrão/modelo préconcebido de "formatações". É possível perceber essa dinâmica a partir dos Centros Integrados de Comando e Controle quando nota-se que um dado sistema técnico, ou, na visão de Foucault, determinada tecnologia de segurança, difunde-se por todo território, ultrapassando os limites estaduais - e até mesmo das regiões metropolitanas - criando redes de proximidade relativa. Uma mesma forma-conteúdo (CICC's - homogeneização), da qual espera-se uma determinada função (fragmentação - comando e controle), estrutura territórios e cria uma coesão a partir das redes, constituindo, simultaneamente, graus de hierarquia.

Sendo assim, o processo de hierarquização estrutura as "formatações" que emergem do processo de homogeneização e as "funcionalidades" do processo de fragmentação - ou seja - é possível perceber um outro processo, o processo de estruturação, que consiste em ratificar formatações $e$ funcionalidades, isto é, validar ou normatizar/normalizar formas-conteúdos e funções, exprimindo o poder na espacialidade e a espacialidade do poder.

Neste sentido, o processo de hierarquização é formalizador, uma vez que, ao ratificar as "formatações" que advém do processo de homogeneização, manifesta seu poder de "formalizar". Considerando a dimensão da fragmentação, a hierarquização é funcionalizadora o processo de hierarquização ratifica as "funcionalidades", manifestando seu poder de funcionalizar. Portanto, no interior do processo de hierarquização - conjugado em sua tríade - e em diálogo com forma-funçãoestrutura, podemos apreender outra tríade: estruturação-formalização-funcionalização, que correspondem à dimensão biopolítica e, destarte, às relações de poder no/do espaço.

Afirmamos que é a partir da estruturação-formalização-funcionalização do/no espaço da vida cotidiana que se garante, tanto na região metropolitana ou nas megarregiões, a unidade do conjunto, a coesão, e no âmbito do controle e da segurança, a coerção.

\section{Referências}

BAUMAN, Z. Medo líquido. Rio de Janeiro. Zahar, 2008. . Confiança e medo na cidade. Rio de Janeiro. Zahar, 2009.

BECK. U. Sociedade de risco: ruma a outra modernidade. São Paulo. Ed.34, 2ª edição, 2010. FOUCAULT, M. Segurança, Território, População. São Paulo, Martins Fontes, 2008.

HAESBAERT, Rogério. Viver no limite: território e multi/transterritorialidade em tempos de insegurança e contenção. 1 ed. Rio de Janeiro, Bertrand Brasil, 2014, ISBN 9788528615777.

Do telecontrole à "ocupação": in-segurança e contenção territorial na metrópole carioca. In: Ferreira, Alvaro; Rua, João; Mattos, Regina Célia de (Org). Desafios da metropolização. Rio de Janeiro. Consequência, 2015.p.225-251.

. Vigiar e Punir: nascimento da prisão. Petrópolis. Vozes, 29a edição, 2004.

LEFEBVRE, H. Espaço e Política. Belo Horizonte, UFMG, 2008.

LENCIONI, S. Reconhecendo metrópoles: território e sociedade. In: Metrópole - governo, sociedade e território. SILVA, C. A. da. FREIRE, D. G. \& OLIVEIRA, F. J. G. de (orgs.). Rio de Janeiro: DP\&A: Faperj, 2006. 
. Da cidade e sua região à cidade-região. In: Panorama da Geografia Brasileira I. SILVA, José Bozacchielo da et al (org.). São Paulo: Annablume, 2006.

Redes, Coesão e Fragmentação do território metropolitano. [ONLINE] Vol. XIV, 2010. Disponível em: <http://www.ub.edu/geocrit/sn/sn-331/sn-331-69.htm>.

. Metropolização do espaço e a constituição de megarregiões. In: FERREIRA, A, RUA, J, MATTOS, R. (Org). Desafios da metropolização do espaço. Rio de Janeiro, Consequência, 2015.

Urbanização difusa e a constituição de megarregiões: o caso de São Paulo-Rio de Janeiro. In: Revista eletrônica e-metropolis, no22, ano 6, setembro de 2015b, p.06-15.

Para além da urbanização metropolitana. Metropolização e regionalização pós-

metropolitana. In: FERREIRA, A, RUA, J, MATTOS, R. (Org). O espaço e a metropolização: cotidiano e ação. Rio de Janeiro, Consequência, 2017, p.147-168.

SANTOS, M. A Natureza do Espaço: Técnica e Tempo, Razão e Emoção. 4. ed. 2. reimpr. - São Paulo: Editora da Universidade de São Paulo, 2006.

. Espaço e método. 5 ed. São Paulo: EdUSP, 2008.

SOUZA, M.A. Recompondo a história da região metropolitana: processo, teoria e ação In: Metrópole: governo, sociedade e território. DA SILVA, C. FREIRE, D. OLIVEIRA, F. Rio de Janeiro, DP\&A editora: FAPERJ, 2006.

SOUZA, M.L. Fobópole: o medo generalizado e a militarização da questão urbana. Rio de Janeiro, Bertrand Brasil, 2008. 